Jurnal Media Pertanian Vol. 4 No. 1 Tahun 2019 Hal. 38 - 44

Media Komunikasi Hasil Penelitian dan Review Literatur Bidang Ilmu Agronomi ISSN print $2503-1279$

ISSN online $2581-1606$

\title{
PEMBERIAN STIMULAN PADA BIDANG SADAP DALAM \\ MEMPENGARUHI PRODUKSI DAN KUALITAS LATEKS TANAMAN KARET (Hevea brasiliensis Muell. Arg.)
}

\author{
${ }^{1}$ Hayata, ${ }^{2}$ Yulistiati Nengsih, ${ }^{3}$ Rahmanto Wibowo \\ ${ }^{1}$ Prodi Agroteknologi, Fakultas Pertanian Universitas Batanghari \\ ${ }^{3}$ Alumni Agroteknologi, Fakultas Pertanian Universitas Batanghari \\ Jl. Slamet Riyadi, Broni Jambi, 36122. Telp. +62741 60103 \\ 1email : hayatahayata82@gmail.com
}

\begin{abstract}
Production increasing of latex on rubber plants can be increased by using a stimulants. One of it is Vicar 10 SL. The purpose of this study was to find out the effect of Vicar 10 SL on the production and quality of latex. This research was carried out in the Kasang Parit Village, Sekernan District, Muaro Jambi Regency, and the Quality Control and Certification Center on Industry and Trade Department in Jambi Province. The study was conducted in July to August 2017. The design used was a completely randomized design with one treatment factor as the Vicar 10 SL application with four levels of treatment, namely; without treatment (V0/control), $1 \mathrm{ml} /$ tree (V1), $2 \mathrm{ml} /$ tree (V2), $3 \mathrm{ml} /$ tree (V3). There were 4 times repeatation on each treatment. Using fingers, a Vicar 10 SL solution was applied to the tapping groove which was adjusted to the treatment, and allowed to keep it 24 hours. Tapping is done in the next morning, by following the grooves and be stored in a cup and left until the latex stoped dripping. Vicar was given once a week during 30 days. Tapping was done 3 times a week. The variables observed were latex production (gram/tree/day), dry rubber content (\%), latex ash content (\%), and latex dirt content (\%). Vicar 10 SL giving in the tapping site with a dose of $2 \mathrm{ml} /$ tree gave the highest yield of latex production (93.38 grams / tree I day) and dry rubber content (75.50\%) and was significantly different compared to the other treatments. Vicar 10 SL giving in tapping site had no significant effect on latex dirt content and latex ash content

Keywords: latex, stimulant, product and quality
\end{abstract}

\begin{abstract}
Abstrak
Peningkatan produksi lateks pada tanaman karet dapat ditingkatkan dengan menggunakan stimulan. Salah satu pemakaian yang digunakan adalah Vikar 10 SL. Tujuan penelitian ini adalah untuk megetahui penggunaan stimulan pada bidang sadap dalam mempengaruhi produksi dan kualitas lateks. Penelitian ini dilakukan di Desa kasang Parit Kecamatan Sekernan Kabupaten Muaro Jambi, dan Balai Pengujian dan Sertifikasi Mutu Barang (BPSMB) Disperindag Propinsi Jambi. Penelitian dilakukan pada bulan Juli sampai dengan Agustus 2017. Rancangan yang digunakan adalah Rancangan Acak Lengkap dengan satu faktor perlakuan pemberian stimulan (Vikar $10 \mathrm{SL}$ ) dengan empat taraf perlakuan yaitu; Tanpa perlakuan (V0/kontrol), $1 \mathrm{ml} /$ Pohon (V1), $2 \mathrm{ml} /$ pohon (V2), $3 \mathrm{ml} /$ pohon (V3). Setiap perlakuan diulang sebanyak 4 kali. Dengan menggunakan jari dioleskan larutan Vikar $10 \mathrm{SL}$ pada alur sadap yang disesuaikan dengan
\end{abstract}


Jurnal Media Pertanian Vol. 4 No. 1 Tahun 2019 Hal. 38 - 44

Media Komunikasi Hasil Penelitian dan Review Literatur Bidang Ilmu Agronomi

ISSN print $2503-1279$

ISSN online $2581-1606$

perlakuan, dan didiamkan selama 24 jam. Penyadapan dilakukan pada pagi hari esoknya, dengan mengikuti alur torehan dan ditampung dalam cawan dan dibiarkan sampai lateks berhenti menetes. Pemberian Vikar dilakukan sekali 7 hari selama 30 hari. Penyadapan dilakukan 3 kali dalam seminggu. Peubah yang diamati adalah produksi lateks (gram/pohon/hari)), kadar karet kering (\%), kadar abu lateks (\%), kadar kotoran lateks (\%). Pemberian stimulan (Vikar 10 SL) pada bidang sadap dengan dosis $2 \mathrm{ml} /$ pohon memberikan hasil yang tertinggi terhadap produksi lateks 93,38 gram/pohon/hari dan kadar karet kering 75,50 \% dan berbeda nyata bila dibandingkan dengan perlakuan lainnya. Pemberian stimulan (Vikar $10 \mathrm{SL}$ ) pada bidang sadap berpengaruh tidak nyata terhadap kotoran lateks dan kadar abu lateks

Kata kunci :lateks, stimulan, produksi dan kualitas

\section{PENDAHULUAN}

Perkebunan karet alam telah menjadi sumber penghasil devisa, maupun sumber penghidupan dan pendapatan masyarakat petani. Karet alam telah menjadi komoditi andalan penghasil devisa kelima setelah minyak bumi, kayu, tekstil dan pariwisata. Karet yang hasilnya biasa disebut lateks, didapat dengan cara melakukan penyayatan pada pohon karet dan kemudian ditampung dalam sebuah wadah tepat dibawah sayatan, maka beberapa saat kemudian akan terkumpul sebuah lateks atau yang lebih sering disebut getah karet.

Produksi lateks dari tanaman karet disamping ditentukan oleh keadaan tanaman dan perumbuhan tanaman, klon unggulan juga dipengaruhi oleh teknik dan manajemen penyadapan. Selama ini usaha peningkatan produksi lateks dilaksanakan melalui berbagai usaha antara alain melaksanakan teknis budidaya seperti menanam klon unggulan, pemupukan dengan dosis yang tepat dan teratur, sistem penanaman dan pemeliharaan yang baik (Nurhakim, 2014)

Pada tanaman karet yang dapat menurunkan mutu dan produksi lateks antara lain pengambilan getah dengan cara yang berlebihan akan menyebabkan tanaman menjadi lemah dan mudah sakit. Eksploitasi pohon karet secara terus menerus akan menyebabkan pohon karet menjadi kering dan akhir mati, apabila penyadapan dilakukan tiap hari. Biasanya pohon karet yang mengalami kekeringan tersebut akan diistirahatkan selama beberapa waktu, tapi bila tidak tampak hasil yang nyata maka pohon karet itu biasanya akan ditebang atau akan dibiarkan tanpa terawat. Masalah kekeringan pohon karet dapat diatasi dengan pemberian stimulan (Ghaida, 2012)

Penggunaan stimulan bertujuan untuk meningkat produksi lateks tanaman dan memperpanjang masa pengaliran lateks. Stimulan adalah suatu campuran terdiri dari minyak nabati misalnya minyak kelapa sawit dengan gemuk alami disebut carier stimulan dan hormon atau bahan aktif lainnya (Setyamidjaja, 1993).

Stimulan lateks umumnya dilaksanakan pada tanaman karet yang telah dewasa dengan tujuan untuk mendapatkan kenaikan hasil lateks sehingga diperoleh penambahan keuntungan bagi pengusaha perkebunan karet. Pemberian stimulan tanpa menurunkan intensitas sadapan akan berpengaruh terhadap pertumbuhan tanaman, terutama tanaman yang masih muda. Karenanya tanaman 
Jurnal Media Pertanian Vol. 4 No. 1 Tahun 2019 Hal. 38 - 44

Media Komunikasi Hasil Penelitian dan Review Literatur Bidang Ilmu Agronomi

ISSN print $2503-1279$

ISSN online $2581-1606$

karet bisa dipacu produksinya dengan stimulan jika telah berusia 16 tahun dan sadapan dengan intensitas rendah (Setyamidjaja, 1993).

Salah satu pemakaian stimulan yang digunakan adalah Vikar 10 SL, pemakaian produk ini dapat juga dilakukan pada pohon karet normal atau sehat untuk mencegah kekeringan pada pohon karet. Vikar 10 SL bekerja dengan cara yang berbeda dengan hormon, produk ini adalah vitamin yaang akan dapat meningkatkan kesehatan pohon karet, dan memberi asupan nutrisi yang diperlukan oleh pohon karet untuk menghasilkan getah karet secara alami sehingga akan memperpanjang masa hidup pohon karet. Pemakaian Vikar 10 SL dengan dosis anjuran $2 \mathrm{ml}$ dan diulang 5 hari sekali dan penyadapan dilakukan 24 jam setelah penggunaan (Juubi, 2014).

Kualitas karet dipengaruhi oleh beberapa faktor yang salah satunya adalah kadar kotoran. Bila kadar kotoran sangat banyak maka akan mempengaruhi kualitas karet, untuk itu perlu diminimalkan kadar kotoran yang terdapat pada karet tersebut. Kadar kotoran merupakan salah satu parameter yang harus dipenuhi dalam meningkatkan mutu karet. Zat-zat pengotor yang terkandung dalam karet adalah batu, pasir, daun, tali rotan, batang karet, pecahan mangkok karet, ranting pohon, dan tatal. Agar standar parameter kadar kotoran memenuhi standar zat - zat pengotor tersebut harus diminimalkan yang terdapat pada karet tersebut (Ritonga, 2008). Berdasarkan uraian di atas dilakukan penelitian yang bertujuan untuk mengetahui penggunaan stimulan pada bidang sadap dalam mempengaruhi produksi dan kualitas lateks.

\section{Tempat dan Waktu Penelitian}

\section{METODE PENELITIAN}

Penelitian ini dilakukan di Desa Kasang Parit Kecamatan Sekernan Kabupaten Muaro Jambi, dan Balai Pengujian dan Sertifikasi Mutu Barang (BPSMB) Disperindag Propinsi Jambi. Penelitian dilakukan pada bulan Juli sampai dengan Agustus 2017.

\section{Rancangan Percobaan}

Rancangan Lingkungan yang digunakan adalah Rancangan Acak Lengkap dengan satu faktor perlakuan pemberian stimulan (Vikar $10 \mathrm{SL}$ ) dengan empat empat taraf perlakuan yaitu; Tanpa perlakuan (V0/kontrol), $1 \mathrm{ml} /$ pohon (V1), 2 $\mathrm{ml} /$ pohon (V2), $3 \mathrm{ml} /$ pohon (V3). Setiap perlakuan diulang sebanyak $4 \mathrm{kali}$, sehingga jumlah unit perlakuan adalah 16 unit satuan percobaan

\section{Pelaksanaan Penelitian}

Tempat penelitian dipilih areal tanaman karet yang seragam dan tanaman berumur 14 tahun yang belum pernah diberi stimulan (Vikar 10 SL). Tanaman yang sudah ditetapkan sebagai sampel alur sadap dibersihkan dari lateks yang belum mengering. Dengan menggunakan jari dioleskan larutan Vikar 10 SL pada alur sadap yang sesuai dengan perlakuan, dan didiamkan selama 24 jam. Penyadapan dilakukan pada pagi hari esoknya, dengan mengikuti alur torehan dan ditampung dalam cawan dan dibiarkan saampai lateks berhenti menetes. Pemberian Vikar dilakukan sekali 7 hari selama 30 hari. Penyadapan dilakukan 3 kali dalam seminggu. 
Jurnal Media Pertanian Vol. 4 No. 1 Tahun 2019 Hal. 38 - 44

Media Komunikasi Hasil Penelitian dan Review Literatur Bidang Ilmu Agronomi ISSN print $2503-1279$

ISSN online $2581-1606$

\section{Peubah yang diamati}

\section{Produksi lateks (gram/pohon/hari)}

Produksi lateks dilakukan dengan cara mengumpalkan lateks setiap kali penyadapan dan ditimbang.

\section{Kadar Karet Kering (\%)}

Pengamatan kadar karet kering dilakukan di Balai Pengujian Sertifikasi Mutu Barang (BPSMB) Disperindag Provinsi Jambi, penghitungan dilakukan dengan menggunakan rumus sebagai berikut:

$$
\begin{aligned}
& \text { KKK(\%) } \frac{B}{A} \frac{(D 1)}{C 1} x \frac{(D 2)}{C 2} \times 100 \% \\
& \text { KKK }=\text { Kadar Karet Kering (\%) } \\
& \mathrm{A} \quad=\text { Berat sampel awal (sebelum digiling) } \\
& \mathrm{B} \quad=\text { Berat sampel setelah digiling } \\
& \mathrm{C} \quad=\text { Berat sampel potongan/cuplikan (sebelum dioven) } \\
& \mathrm{D} \quad=\text { Berat sampel potongan/cuplikan (setelah dioven) }
\end{aligned}
$$

\section{Kadar Abu Lateks}

Pengamatan kadar abu lateks dilakukan di Balai Pengujian Sertifikasi Mutu Barang (BPSMB) Disperindag Provinsi Jambi, penghitungan dilakukan dengan menggunakan rumus sebagai berikut:

$$
\begin{aligned}
& \mathrm{KA}=\frac{\mathrm{A}-\mathrm{B}}{\mathrm{C}} \times 100 \% \\
& \mathrm{KA}=\text { Kadar Abu lateks } \\
& \mathrm{A}=\text { Bobot cawan berikut abu } \\
& \mathrm{B}=\text { Bobot kosong } \\
& \mathrm{C}=\text { bobot potongan sampel lateks yang diuji }
\end{aligned}
$$

\section{Kadar Kotoran Lateks}

Pengamatan kadar kotoran lateks dilakukan di Balai Pengujian Sertifikasi Mutu Barang (BPSMB) Disperindag Provinsi Jambi, penghitungan dilakukan dengan menggunakan rumus sebagai berikut:

$$
\begin{aligned}
& \mathrm{KK}=\frac{\mathrm{A}-\mathrm{B}}{C} \times 100 \% \\
& \mathrm{KK}=\text { Kadar kotoran lateks } \\
& \mathrm{A}=\text { Bobot saringan berikut kotoran } \\
& \mathrm{B}=\text { Bobot saringan kosong } \\
& \mathrm{C}=\text { Bobot sampel uji (potongan lateks uji) }
\end{aligned}
$$

\section{Analisis Data}

Data dianalisis dengan Sidik ragam dan dilanjutkan dengan Uji Duncan New Multiple Rank Test (DNMRT) pada taraf $\alpha 5 \%$ 
Jurnal Media Pertanian Vol. 4 No. 1 Tahun 2019 Hal. 38 - 44

Media Komunikasi Hasil Penelitian dan Review Literatur Bidang Ilmu Agronomi

ISSN online $2581-1606$

\section{Produksi Lateks}

\section{HASIL DAN PEMBAHASAN}

Pemberian stimulan (Vikar $10 \mathrm{SL}$ ) pada bidang sadap berpengaruh nyata terhadap produksi lateks, seperti terlihat pada tabel di bawah ini.

Tabel 1. Rerata produksi lateks pada berbagai perlakukan pemberian stimulan (Vikar 10 SL)

\begin{tabular}{lr}
\hline Perlakuan & Produksi Lateks (g/pohon/hari) \\
\hline $2 \mathrm{ml} /$ pohon (V2) & $93,38 \mathrm{a}$ \\
$1 \mathrm{ml} /$ pohon (V1) & $79,25 \mathrm{~b}$ \\
$3 \mathrm{ml} /$ pohon (V3) & $78,63 \mathrm{~b}$ \\
Kontrol (V0) & $54,00 \mathrm{c}$ \\
\hline
\end{tabular}

Keterangan: Angka-angka yang diikuti oleh huruf kecil yang sama berbeda tidak nyata pada taraf $5 \%$ uji lanjut DNMRT

Dari Tabel 1 terlihat bahwa pemberian stimulan (Vikar 10 SL) pada bidang sadap dengan dosis $2 \mathrm{ml} /$ pohon (V2) memberikan hasil yang tertinggi yaitu 93,38 gram/pohon/hari, hasil ini berbeda nyata bila dibandingkan dengan perlakuan lainnya. Hasil terendah didapatkan pada bidang sadap yang tidak dioles dengan Vikar 10 SL (V0/kontrol), produksi lateks 54,00 gram/pohon/hari

Produksi lateks pada perlakuan $2 \mathrm{ml} /$ pohon (V2) terjadi peningkatan produksi lateks sebesar $72,92 \%$ bila dibandingkan dengan tanpa perlakuan (V0/kontrol), hal ini menunjukkan bahwa Vikar $10 \mathrm{SL}$ dengan dosis $2 \mathrm{ml} /$ pohon telah mampu merangsang sel meningkatkan metabolisme sekunder menghasilkan getah lateks. Menurut Juubi (2014) Vikar 10 SL merupakan multivitamin dengan kandungan 2 chloroethyl phosphonic acid $10 \%$ dapat meningkatkan hasil sadapan karet dalam waktu singkat dan mencegah pohon karet dari penyakit kekeringan. Pengunaan Vikar 10 SL meningkatkan getah karet secara alami tanpa penurunan kualitas DRC(Dry Drubber Content), bahkan Vikar 10 SL akan meningkatkan DRC getah karet.

\section{Kadar Karet Kering Lateks, Kadar Abu Lateks, Kadar Kotoran Lateks}

Pemberian stimulan Vikar 10 SL) pada bidang sadap berpengaruh nyata terhadap kadar karet kering lateks, tapi berpengaruh tidak nyata terhadap kadar abu lateks dan kadar kotoran lateks, seperti terlihat pada tabel di bawah ini.

Tabel 2. Rerata kadar abu lateks, kadar kotoran lateks, kadar karet kering Lateks pada berbagai perlakuan pemberian stimulan (Vikar 10 SL)

\begin{tabular}{lccc}
\hline Perlakuan & $\begin{array}{c}\text { kadar karet kering Lateks } \\
(\%)\end{array}$ & $\begin{array}{c}\text { kadar abu lateks } \\
(\%)\end{array}$ & $\begin{array}{c}\text { kadar kotoran lateks } \\
(\%)\end{array}$ \\
\hline $2 \mathrm{ml} /$ pohon (V2) & $75,50 \mathrm{a}$ & $0,30 \mathrm{a}$ & $0,16 \mathrm{a}$ \\
$1 \mathrm{ml} /$ pohon (V1) & $70,75 \mathrm{a}$ & $0,33 \mathrm{a}$ & $0,17 \mathrm{a}$ \\
$3 \mathrm{ml} /$ pohon (V3) & $65,50 \mathrm{~b}$ & $0,30 \mathrm{a}$ & $0,19 \mathrm{a}$ \\
Kontrol (V0) & $65,25 \mathrm{~b}$ & $0,43 \mathrm{a}$ & $0,20 \mathrm{a}$ \\
\hline
\end{tabular}

Keterangan: Angka-angka yag diikuti oleh huruf kecil yang sama berbeda tidak nyata pada taraf $5 \%$ uji lanjut DNMRT 
Jurnal Media Pertanian Vol. 4 No. 1 Tahun 2019 Hal. 38 - 44

Media Komunikasi Hasil Penelitian dan Review Literatur Bidang Ilmu Agronomi ISSN print $2503-1279$

ISSN online $2581-1606$

Dari Tabel 2 dapat dilihat bahwa pemberian stimulan (Vikar 10 SL) (V2) pada bidang sadap perpengaruh nyata terhadap kadar karet kering lateks, pemberian sebanyak $2 \mathrm{ml}$ memberikan hasil yang tertinggi terhadap kada karet kering lateks yaitu 75,50\%. Tanpa pemberian Vikar 10 SL (V0/Kontrol) kadar karet kering lateks sebesar 65,25\%.

Tingginya kandungan kadar karet kering pada perlakuan V2 menunjukkan bahwa peningkatan kandungan kadar kering lateks meningkat dengan pertambahan produksi lateks.

Pemberian stimulan (Vikar $10 \mathrm{SL}$ ) pada bidang sadap perpengaruh tidak nyata terhadap kadar abu lateks dan kotoran lateks. Secara umum kadar abu pada semua perlakuan jarak tanam pada penelitian ini masih tergolong baik yaitu masih dibawah batas maksimal kadar abu, menurut SNI 1903 : 2000 - Standar Indonesia Rubber yaitu 0,75\%. Menurut Kartowardoyo (1980), Kadar abu lateks dipengaruhi oleh kondisi tanah, musim dan teknis pengolahan. Tanah yang mengandung kalsium tinggi dan pembusukan daun saat musim gugur dapat meningkatkan kadar abu pada lateks. Selain itu proses pengolahan terkait dengan pengenceran juga berpengaruh terhadap kadar abu. Semakin encer lateks yang digumpalkan maka semakin rendah kadar abu karet (Kartowardoyo, 1980).

Menurut SNI 1903 : 2000 - Standar Indonesia Rubber, kadar kotoran pada lateks maksimal 0,20\%. Kadar kotoran merupakan partikel-partikel atau bahan lain yang masuk kedalam lateks. Partikel-partikel tersebut dapat berupa, debu, ranting, daun, kulit pohon, dan mikroorganisme

Untuk menjaga kualitas karet tersebut agar memenuhi standar parameter kadar kotoran yang telah ditetapkan. Kadar kotoran maksimum yang telah ditetapkan oleh Standard Indonesian Rubber ( SIR ) adalah 0,20 \%, yang juga dibandingkan oleh Standard Malaysian Rubber ( SMR ) adalah 0,20 \%. (Ritonga, 2008)

\section{KESIMPULAN}

Pemberian stimulan (Vikar $10 \mathrm{SL}$ ) pada bidang sadap dengan dosis 2 $\mathrm{ml} /$ pohon memberikan hasil yang teringgi terhadap produksi lateks 93,38 gram/pohon/hari dan kadar karet kering 75,50 \% dan berbeda nyata bila dibandingkan dengan perlakuan lainnya.

Pemberian stimulan (Vikar $10 \mathrm{SL}$ ) pada bidang sadap berpengaruh tidak nyata terhadap kotoran lateks dan kadar abu lateks

\section{DAFTAR PUSTAKA}

Ghaida, M. 2012. Permasalahan Umum pada Tanaman Karet. http://drplant.spot.co.id/2012/05/permasalahan-umum-pada-tanaman-karet.html

Juubi, H. 2014. inovasi vitamin karet vikar http://hendrijuubi.blogspot.com/ 2014/11/ inovasi-vitamin-karet-vikar.html 21 Juni 2019

Kartowardoyo, S. 1980. Penggunaan Wallace-Plastimeter Untuk Penentuan. Karakteristik-Karakteristik Pematangan Karet Alam. UGM Yogyakarta

Nurhakim Y.I,, 2014. Perkebunan Karet Skala Kecil Cepat panen Secara Otodidak. Depok.

Ritonga, M. 2008 : Pengaruh Kadar Kotoran Terhadap Kualitas Karet Remah. USU Repository (C) 200. http://repository.usu.ac.id/bitstream/handle/ 
Jurnal Media Pertanian Vol. 4 No. 1 Tahun 2019 Hal. 38 - 44

Media Komunikasi Hasil Penelitian dan Review Literatur Bidang Ilmu Agronomi

ISSN print $2503-1279$

ISSN online $2581-1606$

123456789/13914/09E00093.pdf;jsessionid=7FF76DADEC793144B3A9

8A5600EA52A8? sequence=1 diakses 21 Juni 2019

Setyamidjaja, D. 1993. Karet Budidaya dan Pengolahannya. Kanisius. Yokyakarta 